\title{
QUALITATIVE EDUCATION FOR ROMA STUDENTS: A PEDAGOGICAL MODEL FOR SUSTAINABLE DEVELOPMENT
}

\author{
Daiga Zaķe \\ Daugavpils University, Latvia
}

\begin{abstract}
Inclusion of Roma students in general classrooms at an early age (5-7 years) is the focus of the present research to study the impact of parents and Roma teacher-assistants' involvement in the learning process of Roma minority students. Though Roma people have inhabited Latvia for centuries, a deeply ingrained prejudice towards Roma is persisting among the population at large, resulting in direct and indirect social discrimination. One of the most odious forms of discrimination against Roma is the practice of consigning Roma students to special schools after 'their failure' in the first years of regular elementary schools. Schools, as the primary formal societal institutions that students encounter, have an enormous responsibility in helping to forge a culture of equality, pluralism, tolerance and unity in diversity. The present study deals with the development of intercultural learning and anti-bias classroom organization in order to prevent institutional discrimination and promote the benefits of a culturally heterogeneous society.

Key words: pedagogical model for sustainable development, Roma students, multicultural education, inclusive classroom, Roma teacher-assistant
\end{abstract}

\section{Introduction}

In the context of sustainable education, it is important to solve the exclusion of the students who have been left outside the education system. In a multicultural society, every child has the right to equal and qualitative education; it is prescribed by international normative documentation (for instance, the Declaration of Children's Rights), as well as that of Latvia.

Schools, as the primary formal societal institutions that young people encounter, have the enormous responsibility of helping forge a culture of equality, pluralism, tolerance and unity in diversity. Inclusive education, along with the active participation of parents and society, offers a greater possibility to provide an education to those who are threatened by ignorance and societal rejection: the Roma ethnical minority.

Inclusive education is one of the models of education in a multicultural society. Its nature is based on human rights and is based on the belief that every child, independently of 
his/her, nationality has the right to receive a quality education by studying together with his/her peers. Students are not to be segregated from mainstream schools because of different social reasons, biases or learning difficulties. Mainstream schools are the most appropriate for implementing inclusive education, creating social and cognitive competences, and a positive school atmosphere can promote inclusion best of all. Demands for inclusive education are encouraged by international policy expressed in different international documents: the UNESCO announcement at the Salamanca conference (1994), the European Union Maastricht and Amsterdam anti-discrimination documents, as well as other international documents.

The research provides an analysis about the degree of inclusion of Roma students in the general education system, about the necessity to ensure students' ethnical needs, about how to promote cooperation with parents, as well as an evaluation of how effectively Roma teacher-assistants work.

The research seeks to:

- find out how 5-7 years old students can be included in a multicultural classroom;

- investigate if and how the ethnical needs are provided during the teaching and learning process;

- $\quad$ analyse the learning and inclusion results of Roma students;

- analyse the specifics of the pedagogical process in a multicultural classroom.

This research focuses on exploring the possibilities for inclusion of Roma students in mainstream classrooms in the context of multicultural education.

\section{Description of the situation: The Roma people in Latvia}

Though the Roma people have been living in the territory of Latvia for centuries, there is a considerable difference between the desirable and existing attitudes towards this minority. The Roma people live in the poorest social conditions. One of the reasons for that is the low level of education of Roma people. In today's modern society, it is necessary for every person to have developed social and cognitive skills, which determine the ability or inability to be included socially and technologically. Without quality education, it is impossible to gain access to many aspects of the modern information, technological and economic society. Thus, people start living a vicious cycle: they do not have proper education, they cannot get jobs, they receive inadequate social funding, and this has continued from generation to generation of Roma families.

Even now, the Roma people have limited possibilities of receiving quality education or job. Deeply rooted stereotypes and segregation of the Roma is the reason for direct or indirect social discrimination, which is especially unacceptable in education because the quality of education influences all spheres of a person's life. However, the Roma themselves point out that their attitude towards education has changed and is becoming more positive. In short, they recognise that they need quality education. The figures 
provided in this research show that there is there is significant discrimination that requires immediate solutions.

The Roma culture is a bright and expressive part of the mosaic of Latvian culture. Society's negative and contemptuous attitude to the Roma is mainly undeserved. At the moment, one of the most important tasks is to secure their positions as an equal group of people living in Latvia with equal rights in the area of education and human rights.

The school, as the initial formal institution where a child is involved, plays an especially important role in creating a more equal society. School is a model for the relationship which the present students will use in their relationship with their peers in school and later in their work places, as well as in their personal lives. Because of this, it is essential for schools to model what society wants to see in its grown-ups. One of the needs mentioned by teachers and other school workers in schools with Roma and other minority students is that teachers lack knowledge about how to manage the multicultural classrooms and how to use multiculturalism to their advantage.

\section{Study: Model for inclusion of Roma students in mainstream schools}

Finding ways to obtain knowledge and experience could promote inclusion of the Roma into society. That is why it is important to evaluate, summarise, investigate and synthesise the study results. One of the essential parts of approving an inclusion model is to research the inclusion of Roma students in mainstream educational institutions. The present study documents the process of change in a classroom, school and society. Moreover, a detailed characterisation of the research process, a description of the organization, methodology and analysis of the results are provided.

\section{Characterisation and organization of the research basis}

Methods of study:

1. Theoretical methods: analysis of theoretical literature (pedagogical and psychological literature) and other sources (LR and EU documents, statistic data, strategies, reports).

2. Empirical methods:

- Data collection methods: questionnaires, self-analysis polls, observation, study of portfolios, non-structured interviews, analysis of artefacts, photo and video records.

- Data processing and analysis methods.

Processing the qualitative data was performed by applying a content analysis approach, using techniques of content analysis where the basic sections are analysed by categories, describing the meaning of the analysed information; features of categories and context (Cresswell, 2002); qualitative comparison of observations with the assessment and selfassessment of teachers and teacher-assistants. The final assessment of the model includes a summary of expert opinions and a qualitative analysis. The AQUAD 6 data analysis 
programme was used to process qualitative data and Microsoft Excel was used to process quantitative data.

From 2005-2009, the projects for the Qualitative Education for Roma Students and Roma Students Welcome in School were realised. One of the main goals of the programmes was to overcome the segregation in schools of Roma students by creating and approving a model of inclusion of Roma students that would promote the successful inclusion of Roma students in mainstream schools. Ethnographic research was done before approving the model of inclusion of Roma students. The study comprised 5-7 years old students from nine different classrooms. Teaching the students in these classrooms was performed according to the demands of the mainstream school syllabus, but was done by using the methodology suggested in the Step by Step programme. All classrooms were arranged with the furniture and teaching materials necessary for the teaching and learning process of 5-7 years old students. Simultaneously, nine Roma parents' support centres were established.

The aim of the model is to stimulate the inclusion and adaption of Roma students in the general school system of Latvia. The direct target group of the model is general school teachers. The indirect target group of the model is Roma students. The model is a synthesis of theoretical ideas on multicultural and inclusive education, international normative basic demands and those in Latvia, what has been done in Latvia and other countries and the peculiarities related to the adaptation of Roma pupils as a specific ethnic cultural group. The model is based on the developmental processes of multicultural settings, the content, methods and motives specific to the Roma ethnic minority.

It is a pedagogical model that corresponds to the concepts of human pedagogy, and it is based on experience and action. It covers contents, processes and results, with emphasis on the procedural aspect of action, which means learning by doing and with due regard to socio-cultural aspects of learning. Procedural structure of the model is illustrated in Figure 1.

To improve multicultural schools and provide equality and availability of education to Roma students, the criteria have been developed to assess the results of the pedagogical model of inclusion for Roma students. The criteria will enable us to identify successful educational processes in a multicultural environment, the integration of the Roma students and their readiness to integrate (or their actual integration) in a multicultural school environment. The analysis of psychological and pedagogical literature and the key features of the Roma as a segregated culture allowed to conclude that the criteria selected were appropriate to the specifics of the model, namely that interaction, cooperation and communication constitute the most relevant features indicative of the trend to inclusion. 


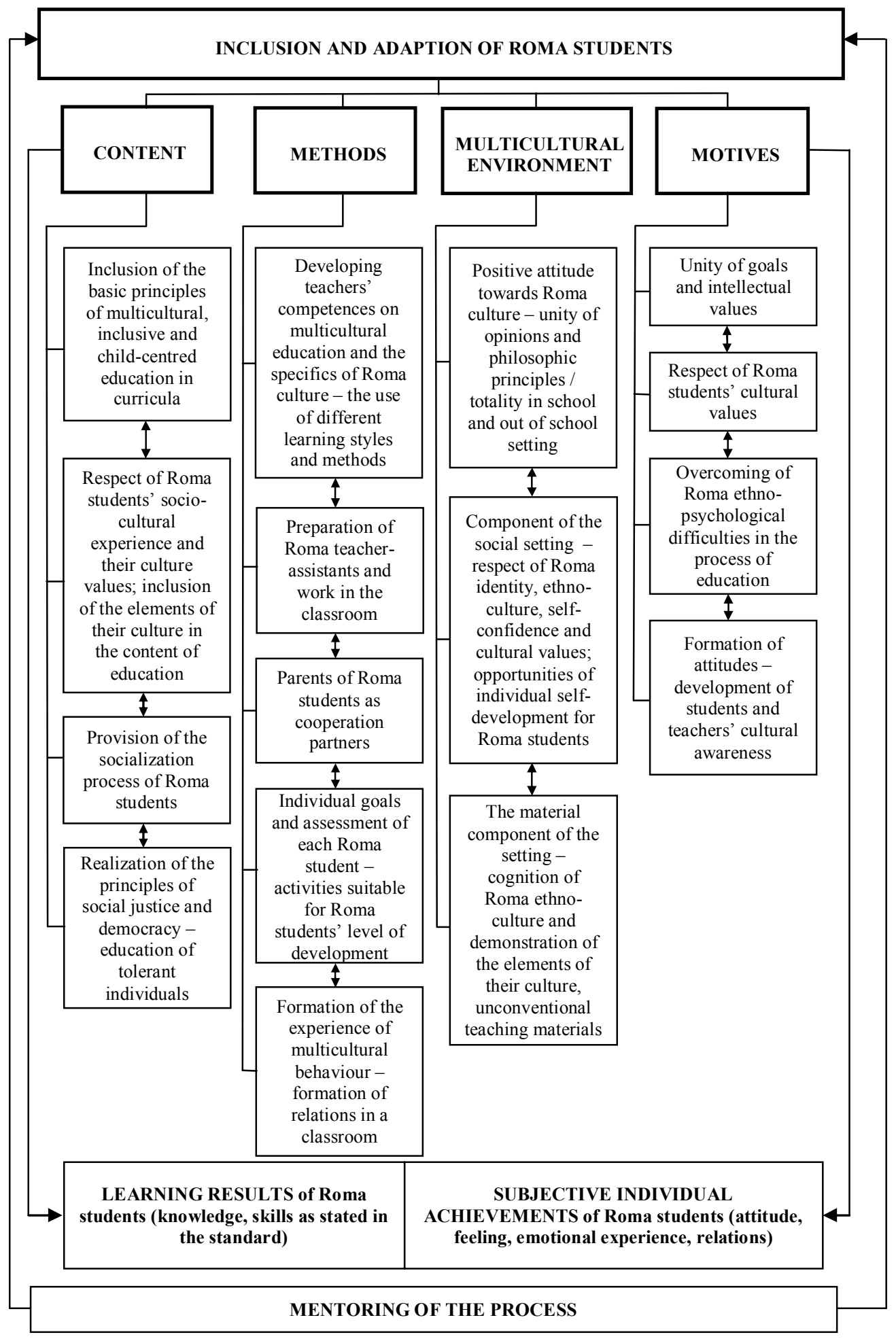

Figure 1. Structure of the pedagogical model 


\section{Analysis of the research results}

Study and analysis of the model and assessment of its impact included:

1. Measurements of inclusion of the Roma students at the beginning and end stages of the implementation of the model against the developed criteria of cooperation, communication, interaction and their respective indicators;

2. Analysis of the impact of the components of model structure on integration and inclusion of Roma students.

The measurements of inclusion of Roma students against the developed criteria and their indices were taken at the beginning (the academic year 2005/2006) and at the end (the academic years 2007/2008 and 2008/2009) stages of the implementation of the model on 50 Roma students with ages ranging from 5 to 7 years.

The following data collection methods were used in taking these measurements:

- observations;

- checklists to determine the degree of inclusion of the students;

- analysis of the students' portfolios;

- non-structured interviews and discussions with teachers and teacher-assistants - Roma people and parents;

- video and photo materials;

- assessment by experts.

The indicators of inclusion and adaption of Roma students were assessed on three levels, according to Chapman (1990):

- actual development level: self-regulated attitudes and actions;

- approximate development zone/level: attitudes and actions based on experience;

- frustration level: situation-based attitudes and actions.

The data obtained by comparing the indicators of inclusion and adaption levels of Roma students at the beginning and end of the implementation of the model against the criteria interaction, cooperation and communication demonstrates that all Roma students who started education during the period of study successfully integrated in the overall education, while significant growth of the students, both academic and social, is observed in the social sphere. Assessment of the integration of the students by levels against all criteria, the number of Roma students experienced a significant decrease of their frustration levels and significant growth on the actual development level (Figure 2). 


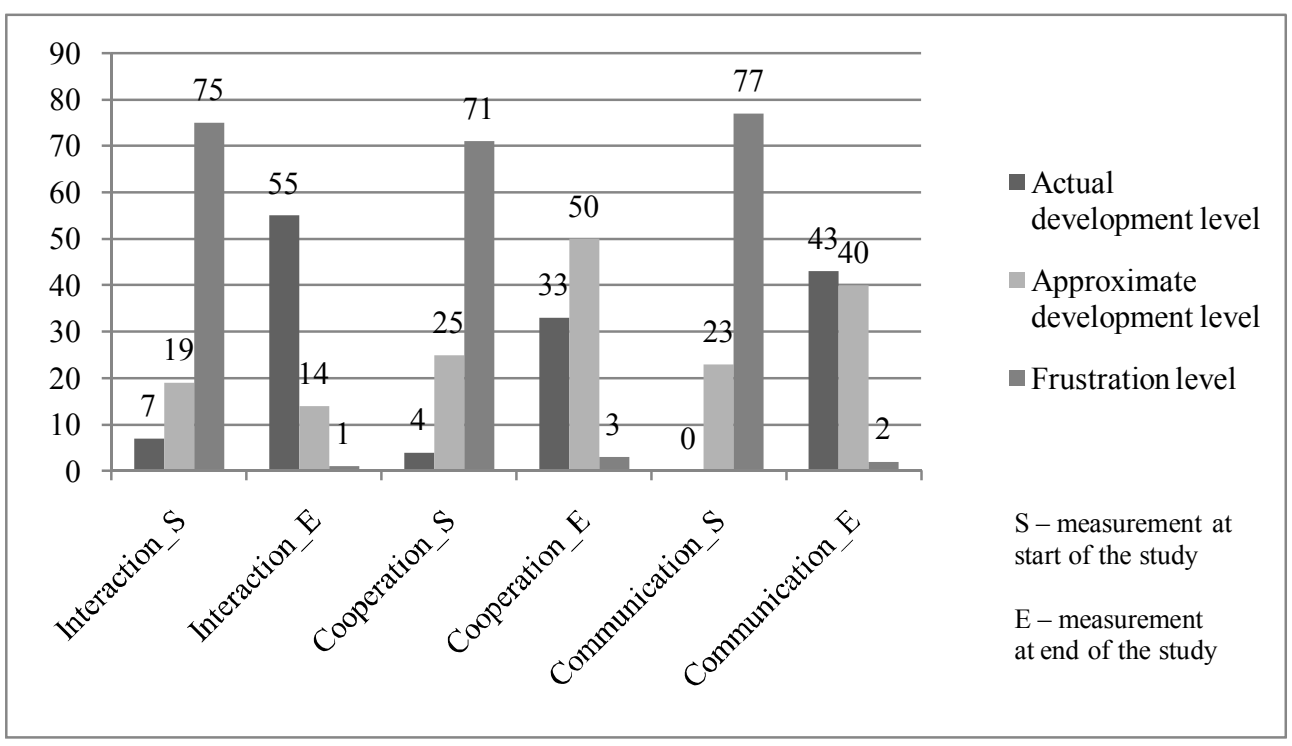

Figure 2. Comparison of the inclusion and integration levels of Roma students against criteria (\%)

\section{How the ethnic needs of students' interaction are provided}

An important aspect of the project to integrate Roma students is to include elements of Roma culture, language, traditions and history in the classroom environment and in the teaching and learning process. One of the features of an inclusive classroom is that the classroom environment reflects the individualities of all nationalities represented in the class by its students - Latvians, Roma or others. Symbols, art, books, music and other materials reflecting the culture naturally adapt themselves to everyday life and activities of the classroom and school. In the places where the present research was carried out, Roma cultural elements had to be present in the classroom environment.

One of the ways to ensure the ethnic needs of students is to introduce at least some of the cultural elements in the classroom, which reveals that the child belongs to a different ethnical group or nationality. A variety of cultural elements in the classrooms was observed - books, signs and posters in the native language of the students, songs and poems learned in different languages, toys typical to different nationalities sitting in the classrooms, dolls dressed in national costumes, pictures showing national traditions, customs and habits of everyday life. It is impossible to create an atmosphere of an inclusive classroom and promote dignity and respect for the Roma language if the students do not have an opportunity to hear and get to know it. The pedagogues were strong in their opinion about the students' books in the Latvian and Roma languages, which were translated and published during the project.

The multiethnic classroom environment is also enriched with the teaching materials prepared by parents in parent workshops. These are the materials which reflect peculiarities of Roma culture: Roma national costumes for dolls, self-made books in the Latvian, 
Russian and Roma languages, table games reflecting national features, national interior decorations, different signs and posters in classrooms in the Roma language.

According to the observations by inclusive education specialists, elements of multicultural education in all the project classrooms were noticed. Furthermore, the professional level of pedagogues considerably promoted the teachers' mutual cooperation in providing bilingual education. The observations also reveal the fact that the inclusion of Roma students in mainstream schools must be a complex activity since the following activities must be carried out simultaneously:

- $\quad$ arranging the educational environment to correspond to students' needs;

- training pedagogues and Roma teacher-assistants to work with Roma students and parents;

- $\quad$ encouraging and training of Roma parents and community leaders;

- creating an anti-bias attitude towards Roma people in the community.

\section{Roma nationality of the teacher-assistant}

It is essential to involve Roma teacher-assistants in the work of the classroom. The main Roma teacher-assistant is supposed to help 5-7 years old Roma students to overcome difficulties which are caused by entering an unknown cultural environment (different language, new routine and order). At the same time, it is also helpful for the classroom teacher to get the Roma child involved in teaching and learning activities and gain the cooperation of Roma families. Roma teacher-assistants helped the Roma language be heard in the classrooms, and they introduced the specific features of Roma people.

Roma teacher-assistants worked in six mainstream educational institutions in groups with 5-7 years old students. Teachers, having analysed the work of Roma teacherassistants, pointed out that they have made a considerable progress. Both the class teachers and their new assistants felt confused when starting to do something so unusual. Teachers did not know how to employ their assistants; they were afraid to ask too much of them. However, step by step, they learned to cooperate with productive results. Although the teacher-assistants have a different level of education and different life experiences, they all were willing to participate and help educate Roma students. They have received regular consultations. Their topics were chosen according to the local needs and the local teacherassistant's understanding.

To promote the process of change, there were consultations held in schools for all teachers and staff members. It is important to change the attitude of all people working in the school, as well as the environment. It is a significant condition of creating an optimal positive learning experience at an early school age for Roma students.

\section{Specifics of the pedagogical process in a multicultural classroom}

From the conversation with teachers, the problems which arise when working with Roma students were deduced: 
- Language difficulties. Though Roma students pick up Latvian or Russian fast, there are some of them that can communicate only in their native Roma language when they start attending school.

- Insufficient cooperation with parents. Parents usually do not understand their role in the process of educating their children. They do not attend parents' meetings (but they like to participate in the school activities where their students take part).

- Teachers do not feel they are competent to work with minority students.

- Prejudicial attitudes of the staff and other parents to the Roma people.

Teachers recognise that they lack the knowledge and skills to work with students of other cultures and to organize the teaching and learning process so as not to harm the child's personality. The teachers have realised that, to get the maximum interest of Roma parents regarding the children's education, they need new cooperative methods when working with Roma parents. Roma people have their own way of solving problems, they have a different understanding about the value and meaning of education provided by educational institutions, and it sometimes causes frustration among teachers. They feel confused and insecure working in a multicultural classroom. The pedagogues are interested in getting to know more about the history, culture and family traditions of the Roma people.

All classroom teachers of this research positively evaluated the Roma teacherassistants, their role and actions in a classroom. They pointed out that more individualised attention could be paid to Roma students. The assistant is a person who promotes understanding between the teacher and the child. With his/her behaviour and attitude he/she sets an example of how to provide help and support. Teacher-assistants, by observing the actions of the teacher and the students, quickly gain confidence in the importance of regular work and practice. Gradually, they start to realise that it is essential for their students to get a good education.

Roma teacher-assistants are called mediators when working with other Roma parents. They help to explain specific situations to parents from the point of view of the teachers. Roma teacher-assistants are said to be a great support for all students of the group. They love, listen to and care for all students independently of their ethnic or cultural background.

\section{Conclusions}

The model of inclusion of Roma students is oriented towards an anti-bias society. It is possible to conclude that all Roma students who started to attend school during the project were successfully included in the social life of mainstream schools. Furthermore, they felt good, and they had improved their social skills. Nevertheless, inclusion in the learning process causes some problems which can be explained mainly by the lack of experience in individualising the pedagogical process.

The research reveals that multicultural education and upbringing of a tolerant personality promotes Roma students' inclusion in school, which can be provided by meeting students' ethnical needs and creating an atmosphere of cooperation with parents. 
Roma teacher-assistants play an especially significant role in the inclusion of Roma students.

This experience indicates that schools can vitally change the process of inclusion of Roma students in a classroom, as well as the integration of Roma families in the community. In all of the research cases, Roma families felt encouraged to use their Constitutional rights to an equal and quality education for their children. The Roma people are satisfied with the pedagogical process if the pluralistic learning approach is organized in such a way that the ethnical needs of their students are also taken into account.

The research results show that the model of inclusion, which encourages multicultural education, is sustainable. It develops and fosters changes of individual, group and community values and behaviours, thus improving the quality of life. The new approach which is disclosed in this research in the context of sustainable education proposes a way of planning and meeting many burning issues in the future by taking into account the correlation between social, economic and other variables. The research data confirms that this pedagogical model can serve the goals of inclusion and adaptation of Roma students in general education. Thus, the proposed model meets the principles of multicultural and inclusive education, as well as general cultural-educational principles.

The proposed model focuses on the creation of an inclusive and multicultural school, where students of different cultural backgrounds study together successfully, by pointing out that the inclusion of Roma students in the system of general education is not only a legal provision to guarantee them an equal education, but also a manifestation of a democratic society. This model provides a successful example of a best practice that might be useful for teachers, education administrators and education policy makers.

\section{References:}

Creswell, J. W. (2002). Quality inquiry and research design. Choosing among five traditions. Thousand Oaks, CA: Sage.

Daniels, E. R., \& Staford, K. (1997). Creating inclusive classrooms. New York: Open Society Institute.

Hansen, K. A., Kaufmann, R. K., \& Saifer, S. (1997). Creating child-centered classrooms: 6-7 year olds. New York: Open Society Institute.

Jacquclyn, V. R. (2003). Education for social justice. New York: Open Society Institute.

Kaufmann, R. K., \& Walsh, K. B. (1996). Creating child-centered classrooms: 3-5 year olds. New York: Open Society Institute.

Krastina, E., Berzina, Z., \&. Zake, D. (2005). Roma identity in a multicultural school: A case study. Latvia: Center for Education Initiatives.

Salite, I., \& Pipere, A. (2006). Aspects of sustainable development from the perspective of teachers. Journal of Teacher Education and Training, 6, 15-32. 


\section{Acknowledgement:}

This study was supported by ESF project "Support to Implementation of Doctoral Studies at Daugavpils University", agreement No. 2009/0140/1DP/1.1.2.1.2/09/IPA/VAA/015, individual agreement No. 14-21/33-2009/48.

\section{Correspondence:}

Daiga Zaķe, PhD student, Faculty of Education and Management, Daugavpils University, Parades 1, Daugavpils, LV-5401, Latvia. Email: daiga@iic.lv 